\title{
Progressive Bilateral Facial Palsy as a Manifestation of Granulomatosis With Polyangiitis: A Case Report
}

\author{
Sang Mee Jeong, MD, Joo Hyun Park, MD, PhD, Jong In Lee, MD, PhD, \\ Kyung Eun Nam, MD, Jung Soo Lee, MD, PhD, Joo Hee Kim, MD
}

Department of Rehabilitation Medicine, College of Medicine, The Catholic University of Korea, Seoul, Korea

\begin{abstract}
Bilateral facial palsy, which is usually combined with other diseases, occurs infrequently. It may imply a lifethreatening condition. Therefore, the differential diagnosis of bilateral facial palsy is important. However, the etiology is variable, which makes diagnosis challenging. We report a rare case of progressive bilateral facial palsy as a manifestation of granulomatosis with polyangiitis (GPA). A 40-year-old male with otitis media and right facial palsy was referred for electroneurography (ENoG), which showed a 7.7\% ENoG. Left facial palsy occurred after 2 weeks, and multiple cavitary opacities were noted on chest images. GPA was diagnosed by lung biopsy. His symptoms deteriorated and mononeuropathy multiplex developed. The possibility of systemic disease, such as GPA, should be considered in patients presenting with bilateral facial palsy, the differential diagnosis of which is summarized in this report.
\end{abstract}

Keywords Facial nerve diseases, Granulomatosis with polyangiitis

\section{INTRODUCTION}

Facial palsy is associated with heterogeneous etiologies, including infectious, traumatic, neoplastic, neurologic and systemic causes. Unilateral facial palsy is a common disease, the cause of which is idiopathic, but bilateral facial palsy is a rare clinical manifestation [1]. It is important to identify the cause of bilateral facial palsy, but atypical clinical manifestations make the diagnosis difficult. We describe a case of a 40 -year-old male with sequential bilateral facial palsy as a manifestation of granulomatosis with polyangiitis (GPA).

\section{CASE REPORT}

A 40-year male was referred to the Department of Oto-

Received September 21, 2015; Accepted October 19, 2015

Corresponding author: Jung Soo Lee

Department of Rehabilitation Medicine, Uijeongbu St. Mary's Hospital, College of Medicine, The Catholic University of Korea, 271 Cheonbo-ro, Uijeongbu 11765, Korea. Tel: +82-31-820-3178, Fax:+82-31-847-7776, E-mail: drlee71@naver.com

ORCID: Sang Mee Jeong (http://orcid.org/0000-0002-9247-0995); Joo Hyun Park (http://orcid.org/0000-0001-9257-8704); Jong In Lee (http://orcid. org/0000-0002-8844-4807); Kyung Eun Nam (http://orcid.org/0000-0001-5195-4320); Jung Soo Lee (http://orcid.org/0000-0002-3807-4377); Joo Hee Kim (http://orcid.org/0000-0001-5543-121X).

@ This is an open-access article distributed under the terms of the Creative Commons Attribution Non-Commercial License (http://creativecommons.org/ licenses/by-nc/4.0) which permits unrestricted noncommercial use, distribution, and reproduction in any medium, provided the original work is properly cited. Copyright $\odot 2016$ by Korean Academy of Rehabilitation Medicine 

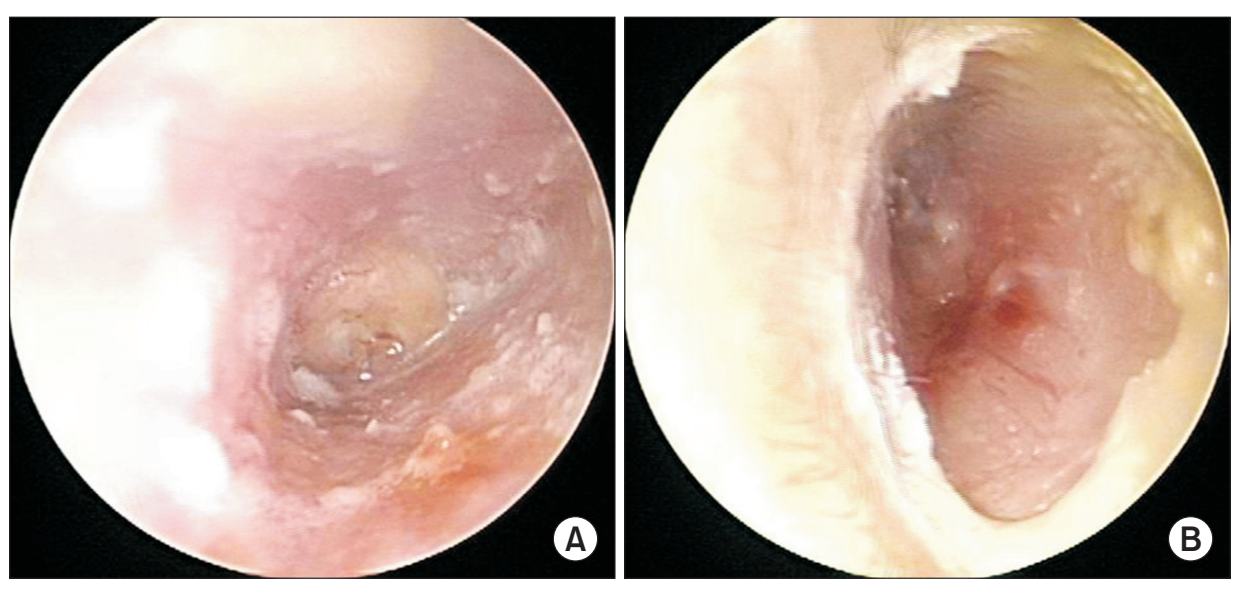

Fig. 1. Otoscopy showed purulent otorrhea and granulation in the right external auditory canal (A), invisible tympanic membrane in the right ear (A), and granulation in the left external auditory canal (B).

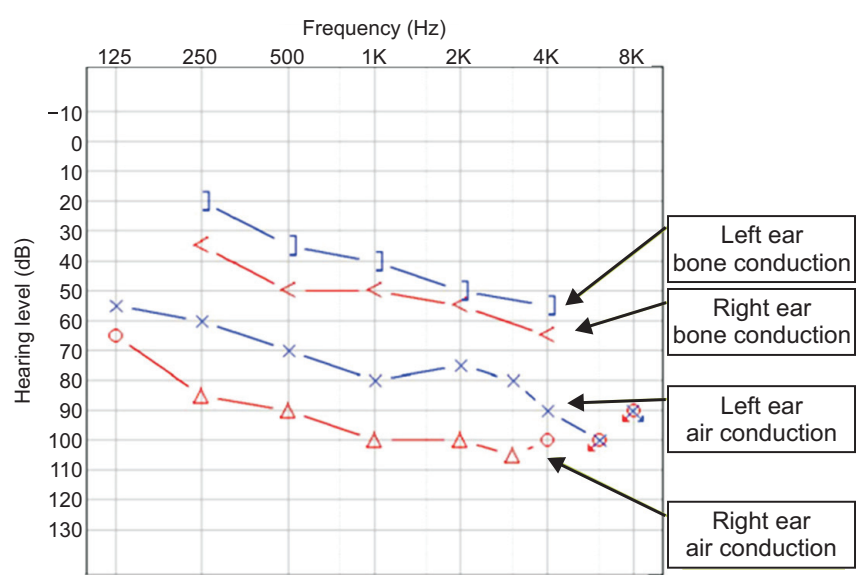

Fig. 2. Pure-tone audiogram showed bilateral mixed type hearing loss with a $45 \mathrm{~dB}$ right air-bone gap and $31.25 \mathrm{~dB}$ left air-bone gap. Red line indicates right ear conduction and blue line left ear conduction.

laryngology from a private clinic for surgical treatment of otitis media. He had no prior illness other than bilateral otorrhea in recent months. Although he had received antibiotics for persistent otorrhea, right peripheral facial palsy of House-Brackmann grading scale (HBGS) IV developed. On admission, bilateral chronic otitis media was observed by otoscopy (Fig. 1), and a pure-tone audiogram showed bilateral mixed hearing loss (Fig. 2). Bilateral otomastoiditis and sinusitis were found (Fig. 3), but no other lesions were detected by temporal and brain computed tomography scan (CT). Electrodiagnostic findings showed that electroneurography (ENoG) in the nasalis muscle was $7.7 \%$ (Table 1), right supraorbital nerve stimulation provoked a contralateral R2 response, but not an ipsilateral R1, R2 response, and left supraorbital nerve stimulation did not evoke a contralateral R2 response in

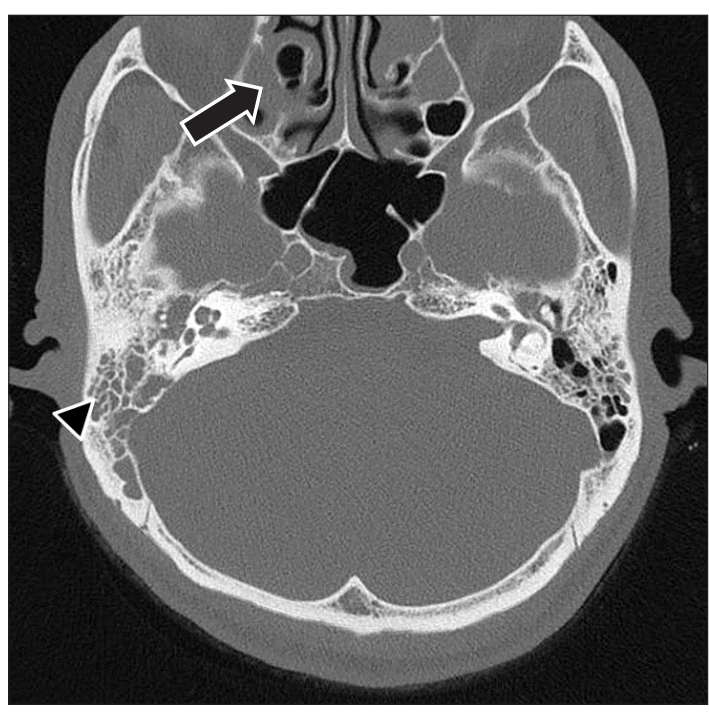

Fig. 3. Temporal bone computed tomography displays otomastoiditis with filling of the mastoid air cells (arrow head) in both middle ear cavities. Sinusitis (arrow) is evident in the bilateral maxillary and left ethmoid air cells.

blink reflex and abnormal spontaneous activities at rest the in right facial muscles. Also, there was no motor unit action potential (MUAP) in the right frontalis muscle and single to discrete MUAP in other facial muscles, which predicted a poor prognosis. He was maintained on antibiotic treatment, underwent right mastoidectomy, tympanoplasty, and facial nerve decompression and was discharged without complications.

However, 1 week later, he was readmitted because of dizziness. The day after re-admission, left facial palsy with HBGS III developed and the recovery of right facial palsy with HBGS IV was not noticed. At this time, temporal bone CT revealed little interval change since the sur- 
Table 1. Electrodiagnostic tests of facial nerves

\begin{tabular}{|c|c|c|c|c|}
\hline \multirow{2}{*}{ Recording site } & \multicolumn{2}{|c|}{ Right facial nerve } & \multicolumn{2}{|c|}{ Left facial nerve } \\
\hline & Onset latency (ms) & Amplitude (mV) & Onset latency (ms) & Amplitude (mV) \\
\hline \multicolumn{5}{|l|}{ On first admission } \\
\hline Frontalis & 2.85 & 0.1 & 3.15 & 1.1 \\
\hline Orbicularis oculi & 2.55 & 0.3 & 2.20 & 1.0 \\
\hline Nasalis & 2.85 & 0.1 & 3.10 & 1.3 \\
\hline Orbicularis oris & 2.45 & 0.1 & 2.50 & 0.7 \\
\hline \multicolumn{5}{|c|}{ On second admission } \\
\hline Frontalis & 2.90 & 0.2 & 2.80 & 0.1 \\
\hline Orbicularis oculi & 2.40 & 0.2 & 2.45 & 0.3 \\
\hline Nasalis & 2.30 & 0.2 & 2.60 & 0.1 \\
\hline Orbicularis oris & 2.50 & 0.1 & 2.60 & 0.1 \\
\hline
\end{tabular}
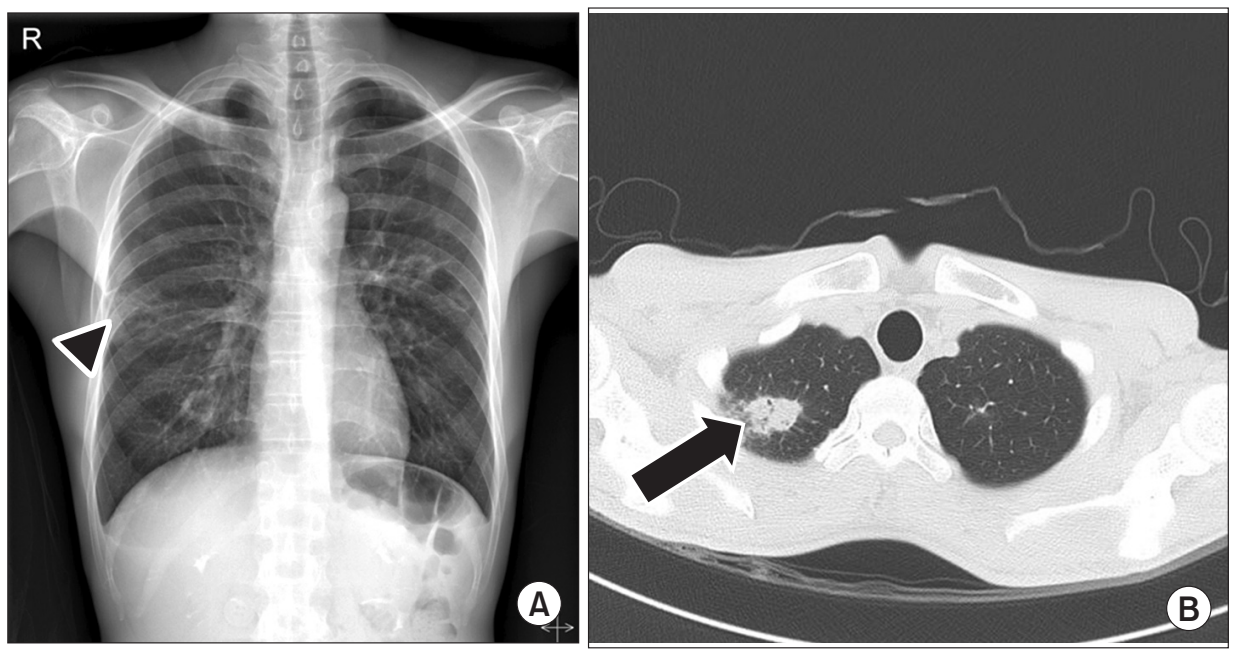

Fig. 4. Imaging study of chest on second admission. (A) Chest Xray shows patchy opacities (arrow head). (B) Chest computed tomography shows multiple cavitary opacities (arrow) and CT findings are suggestive of active tuberculosis, metastasis, or granulomatosis with polyangiitis.

gery performed during his first admission. Electrodiagnostic findings (Table 1) showed a decreased amplitude of the compound action potential of both facial muscles, no $\mathrm{R} 1$ and R2 response in both blink reflexes, abnormal spontaneous activities at rest in all bilateral facial muscles, no MUAP in bilateral frontalis muscles and single to discrete MUAP in other facial muscles. Chest X-ray revealed patchy opacities of both lung fields and chest CT revealed multiple cavitary opacities with large nodules and small consolidations, which suggested the possibility of tuberculosis, GPA, or metastasis (Fig. 4). A diagnostic workup (Table 2) for lung lesions included bronchoscopy, urinalysis, tuberculin test, and autoimmune markers such as anti-neutrophil cytoplasmic antibodies (ANCA), rheumatoid factor, anti-nuclear antibodies (Ab), complement 3 and 4, immunoglobulin G, A, and M, anti SS-A/Ro $\mathrm{Ab}$, anti SS- $\mathrm{B} / \mathrm{La} \mathrm{Ab}$, anti-myeloperoxidase $\mathrm{Ab}$, and anti- proteinase-3 Ab. Anti-proteinase-3 Ab was positive but all other laboratory results, including those of urinalysis, were negative.

Right middle lung wedge resection was performed for lung biopsy, which showed chronic granulomatous inflammation and necrotizing vasculitis in small-tomedium-sized vessels (Fig. 5). Although the laboratory evidence was not sufficient to support a diagnosis of GPA, the histopathologic findings indicated GPA. The patient was treated with steroid and cyclophosphamide. At round the same time, hematuria occurred and parenchymal kidney disease was observed in urinary tract CT. Bilateral uveitis and ulcerative keratitis were detected on slit-lamp examination (Fig. 6) and his visual acuity was 0.63 in the right eye and 1.0 in the left eye at that time.

His tingling sense and weakness of all extremities developed at 1 year after symptom onset and a third elec- 
trodiagnostic study revealed mononeuropathy multiplex (Table 3). At 18 months after symptom onset, the patient was hospitalized with dyspnea. He was diagnosed with Pneumocystis carinii and cytomegalovirus pneumonia and nasal septal perforation. His vision worsened and visual acuities were hand motion of the right eye and 0.16 of the left eye since symptom onset. His condition is worsening despite continuous treatment. The clinical course of the patient is summarized in Table 4.

Table 2. Laboratory results

\begin{tabular}{|cc}
\hline \multicolumn{1}{c}{ Test } & Result (reference) \\
\hline Tuberculin test & Negative \\
$\begin{array}{c}\text { Mycobacterium tuberculosis } \\
\text { (PCR \& hybridization) }\end{array}$ & Negative \\
ANCA & Negative \\
Rheumatoid factor (IU/mL) & $86.1(0-20)$ \\
Anti-nuclear Ab & Negative \\
\hline C3 (mg/dL) & $137(76-139)$ \\
C4 (mg/dL) & $28.2(12-37)$ \\
\hline IgG (mg/dL) & $1,384(870-1,700)$ \\
\hline IgA (mg/dL) & $431(110-410)$ \\
\hline IgM (mg/dL) & $142(33-190)$ \\
\hline Anti SS-A/Ro Ab & Negative \\
\hline Anti SS-B/La Ab & Negative \\
Anti MPO Ab & Negative \\
\hline Anti PR3 Ab & Positive \\
\hline Microangiopathic & $0-1 / \mathrm{HPF}$ \\
hemolytic anemia & $0-1 / \mathrm{HPF}$ \\
\hline WBC (urine) & $0-1 / \mathrm{HPF}$ \\
\hline RBC (urine) & $<3 / \mathrm{HPF}$ \\
\hline Dysmorphic RBC (urine) & \\
\hline
\end{tabular}

PCR, polymerase chain reaction; ANCA, antineutrophil cytoplasmic antibodies; Ig, immunoglobulin; Ab, antibody; MPO, myeloperoxidase; PR3, proteinase-3; HPF, high-power field; WBC, white blood cell; RBC, red blood cell.

\section{DISCUSSION}

Unilateral facial palsy has an incidence of about 25 per 100,000 population and is mostly idiopathic [2]. Bell's palsy is the most common cause of unilateral idiopathic facial palsy, accounting for approximately $70 \%$ of cases [2].

Bilateral facial nerve palsy is more unusual than unilateral facial palsy [3]. May and Klein [4] reported that bilateral facial palsy occurs in only $2 \%$ of patients with facial palsy. When bilateral peripheral facial palsy occurs simultaneously or subsequently, a diagnostic workup is necessary because most of causes are systemic disease, and some are life-threatening. The diagnostic modalities of bilateral peripheral facial palsy are listed in Table $5[1,3]$. Therefore, the top priority in the evaluation of bilateral facial palsy is to rule out life-threatening condition. If it is suspected, the patient should be hospitalized for close observation and diagnostic workup, including

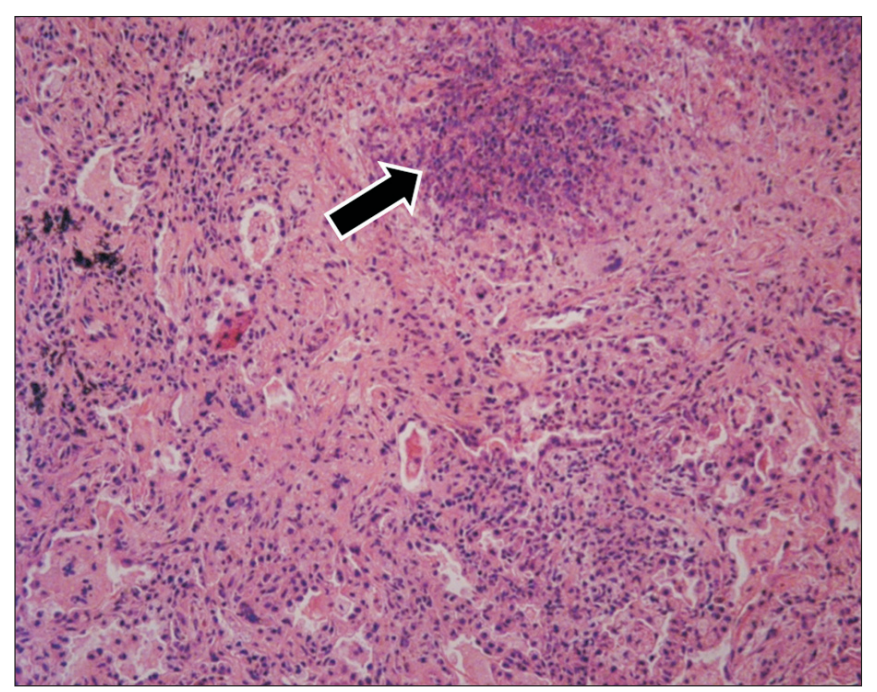

Fig. 5. Histopathological finding of a lung specimen reveals chronic granulomatous inflammation (arrow) and necrotizing vasculitis (H\&E stain, $\times 250$ ).
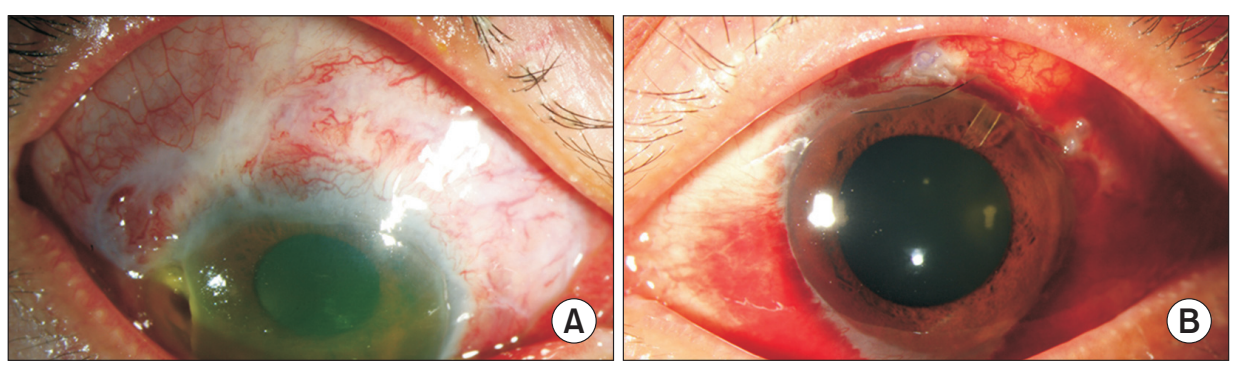

Fig. 6. Bilateral uveitis and ulcerative keratitis were observed upon slit-lamp examination $(\mathrm{A}$, right eye; B, left eye). 
Table 3. Electrodiagnostic tests of the upper and lower extremities

\begin{tabular}{|c|c|c|c|c|c|c|c|}
\hline \multirow{2}{*}{ Nerve-Recording site } & \multirow{2}{*}{ Stimulation site } & \multicolumn{3}{|c|}{ Right } & \multicolumn{3}{|c|}{ Left } \\
\hline & & Lat $^{\text {a) }}(\mathrm{ms})$ & $A m p^{b)}$ & $\mathrm{CV}(\mathrm{m} / \mathrm{s})$ & Lat $^{\text {a) }}(\mathrm{ms})$ & $A m p^{b)}$ & $\mathrm{CV}(\mathrm{m} / \mathrm{s})$ \\
\hline \multicolumn{8}{|l|}{ Sensory } \\
\hline Median & Wrist & 3.00 & 21.9 & & 3.40 & 14.9 & \\
\hline Ulnar & Wrist & 2.90 & 35.3 & & 3.20 & 3.5 & \\
\hline Dorsal ulnar cutaneous & Wrist & 2.60 & 32.1 & & 2.60 & 6.5 & \\
\hline Sural & Calf & \multicolumn{2}{|c|}{$\mathrm{NE}$} & & 2.90 & 7.6 & \\
\hline Superficial peroneal & Lateral leg & & & \multicolumn{4}{|c|}{ NE } \\
\hline \multicolumn{8}{|l|}{ Motor } \\
\hline \multirow[t]{2}{*}{ Median-APB } & Wrist & 2.95 & 10.7 & - & 3.25 & 6.6 & - \\
\hline & Elbow & 6.95 & 10.3 & 57.5 & 6.95 & 6.4 & 55.4 \\
\hline \multirow[t]{3}{*}{ Ulnar-ADM } & Wrist & 2.15 & 6.3 & - & 2.15 & 5.1 & - \\
\hline & Below elbow & 5.25 & 6.2 & 58.4 & 5.25 & 4.8 & 59.7 \\
\hline & Above elbow & 7.25 & 6.0 & 52.5 & 7.25 & 4.0 & 55.6 \\
\hline \multirow[t]{2}{*}{ Peroneal-EDB } & Ankle & \multicolumn{2}{|c|}{ NR } & \multicolumn{4}{|c|}{ NR } \\
\hline & Fibular head & \multicolumn{2}{|c|}{ NR } & \multicolumn{4}{|c|}{ NR } \\
\hline \multirow[t]{2}{*}{ Peroneal-TA } & Fibular head & 2.50 & 3.4 & - & 2.50 & 3.1 & - \\
\hline & Popliteal fossa & 4.30 & 3.1 & 55.6 & 4.25 & 3.0 & 62.9 \\
\hline \multirow[t]{2}{*}{ Tibial-AH } & Ankle & 3.15 & 3.9 & - & 3.55 & 5.7 & - \\
\hline & Popliteal fossa & 10.35 & 3.8 & 44.4 & 10.95 & 5.3 & 43.2 \\
\hline \multicolumn{8}{|l|}{ F-wave } \\
\hline Median & Wrist & 25.65 & - & - & 23.45 & - & - \\
\hline Tibial & Ankle & 44.10 & - & - & 43.85 & - & - \\
\hline
\end{tabular}

$\mathrm{CV}$, conduction velocity; $\mathrm{APB}$, abductor pollicis brevis muscle; ADM, abductor digiti minimi muscle; EDB, extensor digitorum brevis muscle; $\mathrm{TA}$, tibialis anterior muscle; $\mathrm{AH}$, abductor halluces muscle; NR, no response; NE, not evoked.

${ }^{a)}$ Latencies in onset latency on motor nerve conduction, in peak latency on sensory nerve conduction and minimum latency on F-wave study are measured, ${ }^{\text {b) }}$ amplitudes on motor nerve conduction are measured in millivolts $(\mathrm{mV})$ and in microvolts $(\mu \mathrm{V})$ on sensory nerve conduction.

Table 4. Timeline of clinical course since the first facial palsy

\begin{tabular}{|c|c|c|c|c|c|c|c|}
\hline & \multicolumn{7}{|c|}{ Time (wk) } \\
\hline & Sx onset & 3 & 4 & 6 & 8 & 11 & 57 \\
\hline Admission & & & mission & Second admi & ission & $\begin{array}{l}\text { Third } \\
\text { admission }\end{array}$ & $\begin{array}{l}\text { Fourth } \\
\text { admission }\end{array}$ \\
\hline Symptom & $\begin{array}{l}\text { Otorrhea } \\
\text { Rt. facial palsy }\end{array}$ & - & - & $\begin{array}{l}\text { Dizziness } \\
\text { Lt. facial palsy }\end{array}$ & - & - & $\begin{array}{l}\text { General } \\
\text { weakness }\end{array}$ \\
\hline Lab test & & & EDX & $\begin{array}{l}\text { Chest CT } \\
\text { Second EDX } \\
\text { Tuberculin test (-) } \\
\text { ANCA (-) \& other } \\
\text { autoimmune Ab (-) } \\
\text { Urinalysis (-) }\end{array}$ & $\begin{array}{l}\text { MPO Ab (-) } \\
\text { PR3 Ab (+) }\end{array}$ & $\begin{array}{l}\text { Rt. middle } \\
\text { lung wedge } \\
\text { resection }\end{array}$ & Third EDX \\
\hline Treatment & & - & $\begin{array}{l}\text { ENT } \\
\text { opera }\end{array}$ & - & - & - & - \\
\hline
\end{tabular}

Sx, symptom; Lab, laboratory; EDX, electrodiagnostic study; CT, computed tomography; ANCA, anti-neutrophil cytoplasmic antibodies; Ab, antibodies; MPO, myeloperoxidase; PR3, proteinase-3; Rt., right; Lt., left. 
Table 5. Causes of bilateral peripheral facial palsy $[1,3,9,10]$

\begin{tabular}{|c|c|}
\hline Cause & Example \\
\hline Trauma & $\begin{array}{l}\text { Bilateral temporal bone fracture } \\
\text { Mandibular fracture } \\
\text { Parotid surgery } \\
\text { Electrical injury } \\
\text { Forceps delivery }\end{array}$ \\
\hline Infection & $\begin{array}{l}\text { Borrelia burgdorferi, } \\
\text { Treponema pallidum } \\
\text { Mycobacterium tuberculosis } \\
\text { Mycobacterium leprae } \\
\text { Mycoplasma pneumoniae } \\
\text { Leptospira interrogans } \\
\text { Clostridium tetani } \\
\text { Epstein-Barre virus } \\
\text { Herpes simplex virus } \\
\text { Human immunodeficiency virus (HIV) } \\
\text { Varicella zoster virus } \\
\text { Rubella virus } \\
\text { Poliovirus }\end{array}$ \\
\hline $\begin{array}{l}\text { Autoimmune } \\
\text { or unknown }\end{array}$ & $\begin{array}{l}\text { Guillain-Barre syndrome } \\
\text { Sarcoidosis } \\
\text { Amyloidosis } \\
\text { Granulomatosis with polyangiitis } \\
\text { Kawasaki disease } \\
\text { Systemic lupus erythematosus } \\
\text { Sjogren syndrome } \\
\text { Scleroderma } \\
\text { Periarteritis nodosa } \\
\text { Myasthenia gravis } \\
\text { Multiple sclerosis } \\
\text { Behcet's disease }\end{array}$ \\
\hline Neoplasm & $\begin{array}{l}\text { Leukemia } \\
\text { Tumors or metastasis } \\
\text { Middle-ear adenoma } \\
\text { Facial cyst or neurinoma } \\
\text { Fibrous dysplasia of temporal bone } \\
\text { Hemangioma }\end{array}$ \\
\hline Metabolic & $\begin{array}{l}\text { Diabetes mellitus } \\
\text { Alcoholic neuropathy } \\
\text { Acute porphyria }\end{array}$ \\
\hline Toxic & $\begin{array}{l}\text { Vincristine } \\
\text { Ethylene glycol } \\
\text { Paclitaxel } \\
\text { Linezolid }\end{array}$ \\
\hline Genetic & $\begin{array}{l}\text { Familial } \\
\text { Osteoporosis } \\
\text { Mobius syndrome } \\
\text { Melkersson-Rosenthal syndrome } \\
\text { Kennedy's disease } \\
\text { Amyotrophic lateral sclerosis }\end{array}$ \\
\hline Iatrogenic & External carotid artery embolization \\
\hline Idiopathic & Bell's palsy \\
\hline
\end{tabular}

neurologic examination. CT and MRI are useful for identifying central nervous system lesions, skull fractures, and tumor lesions. The workup should include a complete blood cell count, antibody tests, erythrocyte sedimentation rate, and urinalysis.

Of post-infectious causes, the most common cause of bilateral facial palsy is Lyme disease [3], which is responsible for $36 \%$ of cases of bilateral facial palsy. It is the most common vector-borne disease in the United States and Europe, but rare in Korea [5]. The second most common cause of bilateral facial palsy is Guillain-Barre syndrome (GBS), including Miller-Fisher syndrome. Bilateral facial palsy can be seen in about $5 \%$ of patients with GBS and in around half of fatal cases [2].

GPA is a systemic inflammatory disease characterized by necrotizing granulomas and vasculitis in multiple organs. The prevalence of GPA is around 3 per 100,000 population [6]. It usually presents with head, neck, pulmonary, and renal manifestations [7]. Nasal and paranasal sinus disorder is observed in $90 \%$ of the cases and are the most common primary manifestations. Pulmonary infiltrates or nodules are the second most common manifestation. Ear disorders can be seen in $20 \%-61 \%$ of patients, but are rarely the first and only manifestation [8]. Nervous system involvement is also rare at the initial stage, but mononeuropathy multiplex can develop in $15 \%$ of patients and facial palsy in 5\% [7]. Bilateral facial palsy is an unusual manifestation, and its precise incidence is unclear. Few patients experience bilateral facial palsy; approximately 15 cases have been reported globally, and only 2 in Korea.

Bilateral facial palsy is rare as an initial manifestation of GPA; nevertheless, we discuss below several pitfalls of the diagnostic process experienced in this case. Bilateral facial palsies are caused by systemic diseases other than trauma. We did not approach the symptoms without considering the possibility of systemic disease. In this case, mononeuropathy multiplex was revealed by the third electrodiagnostic test (Table 3). Although electrodiagnostic testing is not critical for confirming GPA in the proposed diagnostic criteria of the American College of Rheumatology, we would be able to provide the referring physician with information to assist diagnosis of systemic disease by performing additional conduction studies in extremities. We suggest that electromyographer should perform additional conduction studies of the extremities 
for evaluation of bilateral facial palsy.

Imaging and laboratory findings should be reviewed prior to electrodiagnostic testing. In this case, patchy opacities at the periphery of the bilateral middle lung fields were indicated on chest X-ray at the time of the first admission; however, these were overlooked (Fig. 4). Consideration of both the abnormal chest radiograph along with bilateral facial palsy would have contributed to early diagnosis which may contribute to symptoms relief.

The diagnosis was confirmed by lung biopsy. The time required to perform a biopsy of the lung delayed confirmation of the diagnosis. The patient's condition has worsened despite receiving continuous treatment. Therefore, differential diagnosis of bilateral facial palsy and appropriate, timely treatment are critical to prevent progression. The possibility of systemic disease, such as GPA, should not be overlooked during evaluation of patients presenting with symptoms of bilateral or recurrent facial palsy.

\section{CONFLICT OF INTEREST}

No potential conflict of interest relevant to this article was reported.

\section{REFERENCES}

1. Oosterveer DM, Benit CP, de Schryver EL. Differential diagnosis of recurrent or bilateral peripheral facial palsy. J Laryngol Otol 2012;126:833-6.

2. Pothiawala S, Lateef F. Bilateral facial nerve palsy: a diagnostic dilemma. Case Rep Emerg Med 2012;2012:458371.

3. Jain V, Deshmukh A, Gollomp S. Bilateral facial paralysis: case presentation and discussion of differential diagnosis. J Gen Intern Med 2006;21:C7-10.

4. May M, Klein SR. Differential diagnosis of facial nerve palsy. Otolaryngol Clin North Am 1991;24:613-45.

5. Lee MG, Cho YH. Lyme disease. J Korean Med Assoc 2004;47:1063-9.

6. Maranhao AS, Chen VG, Rossini BA, Testa JR, Penido Nde O. Mastoiditis and facial paralysis as initial manifestations of Wegener's Granulomatosis. Braz J Otorhinolaryngol 2012;78:80-6.

7. Hoffman GS, Kerr GS, Leavitt RY, Hallahan CW, Lebovics RS, Travis WD, et al. Wegener granulomatosis: an analysis of 158 patients. Ann Intern Med 1992;116:48898.

8. Takagi D, Nakamaru Y, Maguchi S, Furuta Y, Fukuda S. Otologic manifestations of Wegener's granulomatosis. Laryngoscope 2002;112:1684-90.

9. Rontal E, Sigel ME. Bilateral facial paralysis. Laryngoscope 1972;82:607-16.

10. Carswell C, Northey LC, Davies L, Yuki N, Kiernan MC. Progressive bilateral facial weakness. Pract Neurol 2015;15:76-9. 